\title{
¡Nosotros queremos la tierra! Despojo y resistencia en la costa nahua, el caso de la comunidad de Santa María Ostula, en Michoacán, México
}

\section{We want the land! Dispossessions and resistance on the Nahua coast of Michoacán: the case of the community of Santa María Ostula}

\author{
María del Carmen Ventura Patiño \\ Doctora en Ciencias Sociales con especialidad en Antropología Social, Ciesas. Centro de Estudios Rurales. El Colegio de Michoacán. Martínez de \\ Navarrete 505, Col. Las Fuentes, C.P. 59699, Zamora, Michoacán, México, ventura@colmich.edu.mx
}

Recibido: 19 de marzo 2019 || Aprobado: 14 de febrero 2020

Resumen

El análisis del conflicto agrario existente entre los indígenas de Santa María Ostula y pequeños propietarios mestizos de La Placita nos permitirá explicar los procesos de defensa del territorio comunal que sus miembros han emprendido a lo largo de su historia. La dimensión agraria es el punto de partida para entender la complejidad de la disputa entre diversos actores e intereses por la apropiación y aprovechamiento de codiciados bienes naturales propiedad de los nahuas de la costa michoacana, para dar cuenta de las distintas formas de despojo que iniciaron desde la Colonia hasta nuestros días, como parte de los procesos denominados por Harvey de acumulación por desposesión. Proyectos turísticos y mineros, pero también de economías ilegales, acompañados de políticas de seguritización en "clave contrainsurgente" forman parte de los actuales desafíos que enfrentan los comuneros de Santa María Ostula, en el estado de Michoacán, México.

Palabras clave: Territorio; Violencia; Resistencia; Seguritización

\section{Abstract}

The analysis of the current agrarian conflict between the indigenous people of Santa María Ostula and the small, mestizos owners in La Placita allows us to elucidate the processes that community members have implemented over time to defend their communal lands. The agrarian dimension is the starting point of understanding: 1) the complexity of disputes among diverse actors and interests, in order to appropriate and exploit the highly-coveted natural resources belonging to the Nahuas on the Michoacán coast; and 2) distinct forms of dispossession that began in Colonial times and continue today. These dimensions are examined in light of the processes that David Harvey calls 'accumulation by dispossession'. Tourism and mining projects, plus illegal economies, accompanied by public security policies of the "counterinsurgency" type, are just some of the challenges that members of the community of Santa María Ostula -in the state of Michoacán, Mexico- face today.

Key words: Territory; Violence; Resistance; Securitization

Cita sugerida: Ventura Patiño, M.C. (2020). ¡Nosotros queremos la tierra! Despojo y resistencia en la costa nahua, el caso de la comunidad Santa María Ostula, en Michoacán, México. Estudios Socioterritoriales. Revista de Geografía, (27), 039. DOI: https://doi.org/10.37838/unicen/est.27-039 


\section{INTRODUCCIÓN}

Desde el inicio del periodo colonial en la costa nahua del actual estado de Michoacán tuvieron lugar distintos procesos de desposesión: despojo de territorios, extracción de recursos naturales y explotación de fuerza de trabajo. Además de una importante disminución de la población nativa, a consecuencia de los efectos de la conquista, como la destrucción de sus formas de vida, las relaciones inhumanas a las que fueron sometidos, aunado a las epidemias que los asolaron.

En 1524 se reportan las primeras exploraciones en la búsqueda de oro, uno de los metales más preciados por los españoles:

[...] tenemos conocimiento de que cuando Cortés en 1520 le preguntó a Moctezuma en qué parte de su imperio estaban las minas de oro, este le respondió que, 'en cuanto a las minas, tenía noticia, que donde más le solían traer oro y plata era de la provincia de Zacatula hacia el sur'. (Novella, 1996, p. 28)

El propio Hernán Cortés fue dueño de las minas de Motines de Oro, en las que trabajaban seis cuadrillas de esclavos-indios, "sacaban cada ocho días 'ochocientos tamemes (cargador indio) cargados de dicho bastimento' [...] cada cuadrilla sacaba, al término de un año, mil pesos de oro [...] cada esclavo valía diez pesos de oro común" (Acuña, 1987, p. 128, citado en Novella, 1996, p. 33-34). Sin embargo, la explotación "se suspendió o casi se abandonó en 1550"; durante ese mismo período (1526 y 1532) también se registraron las primeras rebeliones en contra del trabajo forzado en las minas (Gerard 1972, p. 192, citado en Gledhill, 2004, p. 168).

No obstante, a la extracción minera le siguió la creación de encomiendas, Zacatula y Colima, a las que estaban sujetos los indígenas y tenían obligación laboral y tributaria: "algunos pueblos en la Provincia de Motín pertenecieron a encomenderos, como Uiztlan, sobre la costa, Amatlan y Motenpacoya [...]" (Novella, 1996, p. 33, cursivas en el original). Poco después, los nahuas fueron desterritorializados de la playa y ubicados en la Sierra para constituir las primeras congregaciones de los pueblos: Maquilí, Pó- maro y Coahuayana; posteriormente se funda Santa María Ostula con indios provenientes de los dos primeros pueblos y de Ixtlahuacán. Para 1658 las encomiendas dejaron de existir.

Durante la mitad del siglo XVII en el partido de Motines, al que pertenecían los pueblos indígenas, surgieron una serie de epidemias que diezmaron seriamente a la población. Ya desde el siglo XVI en una visita del oidor y juez Lebrón de Quiñones, informaba:

Hallé los naturales de aquellas provincias muy perdidos, pobres, fatigados, disminuidos, asolados, en tanto número y grado $[. .$.$] no hay la$ centésima parte de gente que cuando fueron conquistados [...] porque muchos pueblos que ahora quince o veinte años tenían a diez mil indios y más, no se hallan ahora cuarenta o cincuenta.

(Novella, 1996, p. 35)

En ese entonces, "Maquilí contaba con 41 habitantes, Aquila con 38, Alima con 39, Ostula con 48, Pómaro con 48 y Coire con 20" (Cochet, 1991; Sánchez Díaz, 2010, p. 34). Debido a los excesivos tributos, que incluía el pago correspondiente de los difuntos, a la escasez de producción y a la gran mortandad por hambre, en 1785 se registraron algunos motines (Reyes García, 1993).

A pesar de la disminución de su población, los nahuas pudieron mantener la propiedad de sus tierras hasta fines del siglo XVIII. Empero, un nuevo proceso de despojo territorial tuvo lugar, los criollos provenientes de los Altos de Jalisco empezaron a asentarse en la Sierra de Coalcomán y tomaron posesión de superficies importantes a través del arrendamiento y cercamiento de potreros para el pastoreo de su ganado.

Por otra parte, la explotación minera se reactivó en 1807. En Coalcomán se instaló la primera fundición de hierro en la América Hispánica, pero se suspendió en 1811 debido a la guerra de Independencia y a que los nahuas se apoderaron de la fundición y proveían de armas a los insurgentes, infraestructura que fue destruida por los realistas. Posteriormente la ferrería se reactivó, pasando por varios dueños durante todo el siglo XIX. Hasta que a principios del siglo XX dos empresarios norteamericanos y dos ingleses solicitaron a la Agencia Minería de Michoacán 
la concesión de 135 pertenencias de minas de fierro del municipio de Aquila ${ }^{1}$, que traspasaron más tarde a otros inversionistas, entre ellos a la Compañía de Minas de Fierro del Pacífico (Sánchez Díaz, 2013, pp. 125-126). Desde 1998 la empresa denominada Las Encinas filial de Ternium, una de las compañías mineras más grandes del mundo, lleva a cabo la explotación de ese mineral y ha formado parte del proceso de violencia desatado en la región, en años recientes. Todo ello a través de una combinación de explotación legal e ilegal de minerales.

Otro de los embates que tuvieron que enfrentar los nahuas fueron los dispositivos jurídicos liberales en contra de sus propiedades durante el siglo XIX. Se calcula que las comunidades de la costa junto con Coalcomán eran propietarias de cerca de 500 mil hectáreas. La ola migratoria por parte de rancheros mestizos pronto fue expandiéndose hacia la costa, asediando a las otras comunidades (Cochet, 1991). Este proceso de despojo 'hormiga' se vio favorecido por la Ley Lerdo que señalaba que "las tierras comunales debían ser repartidas entre miembros de las extintas comunidades indígenas" (Purnell, 2004, citado en Gledhill, 2004, p. 221). De esta manera, comenzó la legalización del despojo por parte de rancheros y una serie de funcionarios que supieron aprovechar a su favor este nuevo marco jurídico. Otra disposición importante en contra de las comunidades indígenas fue una circular de 1887 que establecía que estas ya no tenían personalidad jurídica y que, por tanto, solo podían representarse en su calidad de grupos de individuos con intereses comunes.

Este conjunto de medidas legales explica la extinción de las comunidades de Maquilí, Coalcomán, Huizontla y Aquila. Por ejemplo, las tierras de Maquilí fueron repartidas y privatizadas incluyendo bosques, pantanos y pastos, en el contexto de las políticas liberales y de la avanzada por parte de los rancheros sobre su territorio.

1 El municipio de Aquila se crea en 1909 en el marco de la Ley Orgánica de División Territorial de Michoacán expedida en ese año. Cuenta con una superficie de 2,311.69 hectáreas. https://es.wikipedia.org/wiki/Municipio_de_Aquila_(Michoac\%C3\%A1n)
Las 25 mil hectáreas propiedad de la comunidad de Huizontla fueron declaradas como 'realengas' y compradas años más tarde por los migrantes rancheros y extranjeros, como el alemán Daniel Grahle y el norteamericano Frank Horace (Gledhill, 2004), por lo que, en ese entonces la comunidad quedó reducida a solo 5 mil hectáreas. Afortunadamente, Huizontla y Aquila lograron reconstituirse después de un difícil proceso de lucha, durante las dos últimas décadas del siglo XX, en el marco de la reforma agraria, aunque con una superficie muy reducida. En lo que concierne a las comunidades de Pómaro, Coire y Ostula, pudieron conservar la mayor parte de sus terrenos comunales. Sin embargo, otra vía de despojo fue el arrendamiento, que permitió el saqueo de los recursos por parte de extranjeros, como sucedió en 1863 en la comunidad de Pómaro, donde "saquearon madera fina que fue vendida a compañías privadas norteamericanas, como la Pacific Timber Company" (Cochet, De Surgi y Leonard, 1988, p. 284).

Con la avanzada ranchera se fueron creando asentamientos, uno de ellos fue en la costa fundando el pueblo de La Placita. Durante las primeras décadas del siglo $\mathrm{XX}$, algunos de estos rancheros solicitaron dotación de tierras, constituyendo el ejido Maquilí en 1965, con 57 beneficiarios y 5.700 hectáreas (Cochet, 1991). En 1967 obtuvieron otra dotación para formar el ejido de La Placita con 1.398 hectáreas para 56 ejidatarios. Este último colinda y afecta parte de las tierras comunales de Santa María Ostula.

Por su parte, las comunidades también hicieron sus propias gestiones agrarias. En 1956 la comunidad de Coire fue la primera que logró el reconocimiento de sus bienes comunales, comprendiendo una superficie de 54.448 hectáreas. En 1960 le siguió Pómaro con una superficie de 75.420 hectáreas, desafortunadamente, en la actualidad "poco menos de la mitad de esas tierras se encuentra ocupada por mestizos" (Marín, 2004, p. 255). En 1964 a la comunidad de Santa María Ostula se le reconoció a su favor una superficie de 19.032 hectáreas, aunque su reclamo comprende una superficie 
mayor, sobre este conflicto agrario hablaremos más adelante. Aquila obtuvo su reconocimiento en 1980 , con una superficie de 20.658 hectáreas. La última comunidad en obtener su reconocimiento fue Huizontla en 1996, después de más de cuatro décadas de gestiones, únicamente con 2.701 hectáreas (Gobierno de México, s/f) de las 25 mil que otrora le pertenecieron. Además, durante este periodo, como una estrategia de reterritorialización los nahuas regresaron a la costa, en donde estuvieron sus antiguos pueblos. La comunidad de Pómaro con los asentamientos costeros de: Tizupan, Cachán de Echeverría, Paso de Noria y Maruata; la comunidad de Coire con: Colola, Motín de Oro y Faro de Bucerías; por su parte Ostula con: Ixtapilla, El Zapote de Madero, La Ticla y el Duín (Marín, 2004).

Así, la historia de la costa nahua michoacana ha estado marcada por el saqueo de sus recursos naturales (minerales y maderables) y por el despojo y apropiación de sus territorios, así como por la explotación de su fuerza de trabajo. No obstante, el proceso de desposesión continúa hasta el siglo $\mathrm{XXI}$, ahora por nuevos y viejos actores: gubernamentales, inversionistas (turísticos y mineros) y los provenientes de economías ilegales; generando un complejo panorama de violencia. Como bien afirma Harvey, las prácticas depredadoras de acumulación han sido permanentes a lo largo de la geografía histórica: "denominar" "primitivo" u "originario" a un proceso en curso parece desacertado, sugiere "sustituir estos términos por el concepto de acumulación por desposesión" (Harvey, 2005).

Estas prácticas de desposesión comprenden la mercantilización y privatización de la tierra y la expulsión forzosa de poblaciones campesinas; la conversión de formas diversas de derechos de propiedad (comunal, colectiva, estatales, etc.) en derechos exclusivos de propiedad privada; la supresión de los derechos sobre los bienes; la mercantilización de la fuerza de trabajo y la eliminación de los modos de producción y de consumo alternativos (autóctonos); procesos coloniales, neocoloniales e imperiales de apropiación de activos (recursos naturales entre ellos) [...]. (Harvey, 2004, p. 116)
La conflictiva historia agraria de Santa María OSTULA

El 17 de enero de 1952 los representantes comunales de Santa María Ostula presentaron una solicitud de confirmación y titulación de bienes comunales (CTBC) ante las autoridades agrarias, para lo cual entregaron documentos coloniales que acreditaban la propiedad de su territorio, sin embargo, fueron declarados por el departamento paleográfico como "insuficientes". Posteriormente, los nahuas entregaron escrituras elaboradas en 1802 y 1803, que fueron declaradas "auténticas" (Resolución Presidencial, 1964). A partir de esta documentación las autoridades agrarias realizaron los trabajos técnicos de medición resultando una superficie de 25.580 hectáreas en posesión de la comunidad. No obstante, una fracción de la colindancia poniente fue reclamada por pequeños propietarios, algunos de ellos, presentaron escrituras que datan de 1911. Posteriormente, en abril de 1964 la Secretaría de Reforma Agraria (SRA) emitió una Resolución Presidencial a favor de Ostula, reconociendo únicamente 19.032 hectáreas. Por su parte, la comunidad se inconformó con la Resolución Presidencial e impidió que esta fuera ejecutada.

Los problemas iniciaron desde los trabajos técnicos de medición, el ingeniero encargado se negó a recorrer los linderos indicados por los comuneros, lo cual fue denunciado a las autoridades correspondientes. De modo que, la SRA envió a otro ingeniero, sin embargo, de nuevo se presentaron los mismos problemas y los trabajos se suspendieron una vez más. Ante estos hechos, la comunidad decidió elaborar una carta dirigida al entonces presidente de la República el Lic. Adolfo López Mateos (1958-1964), en la que señalaba que los pequeños propietarios habían dado dinero a los ingenieros para que estos respetaran sus llamadas propiedades, las cuales invadían las tierras de la comunidad, además que el ingeniero enviado se la pasaba en las fiestas en la localidad de La Placita a "costa de las finanzas de la comunidad"2. En 1971 las autoridades agrarias in-

2 Oficio, 01 de marzo de 1959. Expediente de la comunidad 
tentaron de nueva cuenta ejecutar la Resolución Presidencial, pero con resultados negativos, por la oposición de la comunidad.

Un punto de controversia, que nos interesa exponer aquí, es la mojonera denominada "Mahajuas", que era la colindancia con la comunidad de Maquilí y que puede demostrarse con un documento que data de fines del siglo XVIII, en el cual se relata un proceso que comprende de 1776 a $1779^{3}$. Refiere a un conflicto entre Maquilí y Ostula por unas salineras situadas en la costa. Como parte del procedimiento para resolver el conflicto, las autoridades coloniales realizaron lo que se llamaba una "vista de ojos", consistente en ir al lugar del conflicto y caminar el territorio, así como llamar a una serie de personajes (entre ellos colindantes) para que informaran lo que conocieran sobre el asunto. En este documento que es firmado por las autoridades coloniales puede leerse la descripción detallada del caminamiento efectuado en esos años. Traemos este documento a colación porque en este, las autoridades coloniales reconocen las tierras de la comunidad de Santa María Ostula y se señala la colindancia con Maquilí, como un punto de referencia conocido y aceptado por las partes que es la mojonera denominada "Mahajuas". Incluso durante los trabajos técnicos realizados por ingenieros de la SRA en 1953 señalan en un informe que la comunidad de Maquilí es la colindante. No obstante, pocos años más tarde, en la Resolución Presidencial se asienta que los colindantes de esa fracción son pequeños propietarios, lo cual implicó el reconocimiento legal por parte de las autoridades agrarias de los documentos presentados por los mestizos que reclamaban como propiedad particular esa superficie. Por tanto, dicha fracción fue desagregada del polígono comunal, lo que representó que el límite se recorriera de la mojonera "Majahuas" a la mojonera denominada "149", esto es varios kilómetros sobre la costa en dirección oriente en perjuicio de Ostula.

Santa María Ostula. Departamento Agrario. AGA.

3 Expediente de la comunidad Santa María Ostula. Departamento Agrario. AGA.
No conformes con este despojo, los pequeños propietarios continuaron extendiendo sus propiedades sobre el territorio comunal hacia el predio conocido como "La Canahuancera", ubicado también sobre la costa. Es sobre dicha superficie que reside el actual conflicto, en virtud de que lo reconocido en la Resolución ya no puede ser materia de juicio, es decir, la superficie de la mojonera "Majahuas". Esta invasión provocó obviamente una reacción de la comunidad. En 1997 después de infructuosas y reiteradas gestiones de los nahuas de Ostula para que las autoridades agrarias realizaran un "replanteo de linderos", en asamblea comunal decidieron recuperar las tierras tomando posesión de ellas, no obstante, el gobierno estatal intervino y les dijo: "saben qué muchachos, pues vamos a negociar. Esto se va a resolver, no se preocupen, regrésense a su casa"4. Los comuneros se salieron del predio, pero el problema no fue resuelto (Mapa 1).

Ante el incumplimiento por parte de las autoridades estatales y agrarias, en 2003 la asamblea decidió recuperar nuevamente el predio. Durante la administración del gobernador perredista Lázaro Cárdenas Batel (2002-2008) acordaron que el gobierno estatal se encargaría de resguardar el predio, mientras se dirimía el conflicto ante las instancias agrarias. No obstante, "[...] en cuanto la comunidad se desmovilizó el gobierno olvidó los compromisos, retiró la seguridad que tenía y los pequeños propietarios entraron a los terrenos y los ocuparon, incluso con más intensidad [...]" (Agencia prensa india API, s/f) $)^{5}$. A decir de algunos comuneros: "la comunidad fue engañada por el propio gobierno del Estado"6. En 2004 los pequeños propietarios demandaron a la comunidad ante el Tribunal Unitario Agrario (TUA) con sede en el estado de Colima, cuya resolución emitida en 2008 fue a favor de los

4 Entrevista a asesor, me reservo su nombre para no poner en riesgo su seguridad, debido al contexto de violencia que se vive en la región, 30 de agosto de 2014.

5 Entrevista a un comunero.

6 Entrevista a un miembro del Consejo Comunal, me reservo su nombre para no poner en riesgo su seguridad, debido al contexto de violencia que se vive en la región, 29 de junio de 2019, en el décimo aniversario de la recuperación de las tierras. 
demandantes, interpretando en su beneficio la ubicación de la mojonera "149". Por su parte, la comunidad solicitó un recurso de revisión ante el Tribunal Superior Agrario (TSA), instancia que ratificó dicha sentencia, sin embargo, ordenaba una medida cautelar en el sentido que ninguna de las dos partes tomara posesión del territorio, los pequeños propietarios hicieron caso omiso de esta medida, destruyeron las casas de los comuneros, levantaron sus propias casas y sembraron distintos cultivos.

La comunidad interpuso un amparo directo que se radicó en el Quinto Tribunal Colegiado con sede en la Ciudad de México, autoridad que les concedió el amparo en junio de 2009, dejando sin efecto la resolución del TSA, por haber violado las garantías constitucionales de la comunidad, en particular las reconocidas en los artículos 14 y 16 constitucionales. Pocos días antes de conocer la resolución del TSA la asamblea comunal con la presencia de cerca de
2 mil comuneros acordó una serie de acciones en defensa de su territorio: 1) continuar por la vía jurídica, interponiendo los recursos correspondientes; 2) seguir con las negociaciones con el gobierno estatal y; 3) recuperar las tierras por considerar que estaban en "peligro"7. Por eso el 29 de junio de 2009 decidieron tomar posesión de cerca de 1.300 hectáreas y fundar el campamento denominado Xayakalan:

¡aquí fue la comunidad la que decidió! [...] hay que recuperar las tierras para que nuestros hijos tengan donde trabajar, jnosotros queremos la tierra! ¡No queremos dinero! Ni convenio, inosotros lo que queremos es la tierra y nada más y se acabó, a lo que tope, porque así lo decidimos y así estamos! [...] iNosotros no estamos robando tierra, ni quitando, estamos peleando en la nuestra! [...] ¡si no tenemos tierra, no tenemos futuro! $[\ldots]^{8}$.

7 Entrevista a asesor, me reservo su nombre para no poner en riesgo su seguridad, debido al contexto de violencia que se vive en la región, 30 de agosto de 2014.

8 Entrevista colectiva, miembros que resguardan las tierras comunales, 11 de septiembre de 2009. Campamento Xayakalan en Ostula.

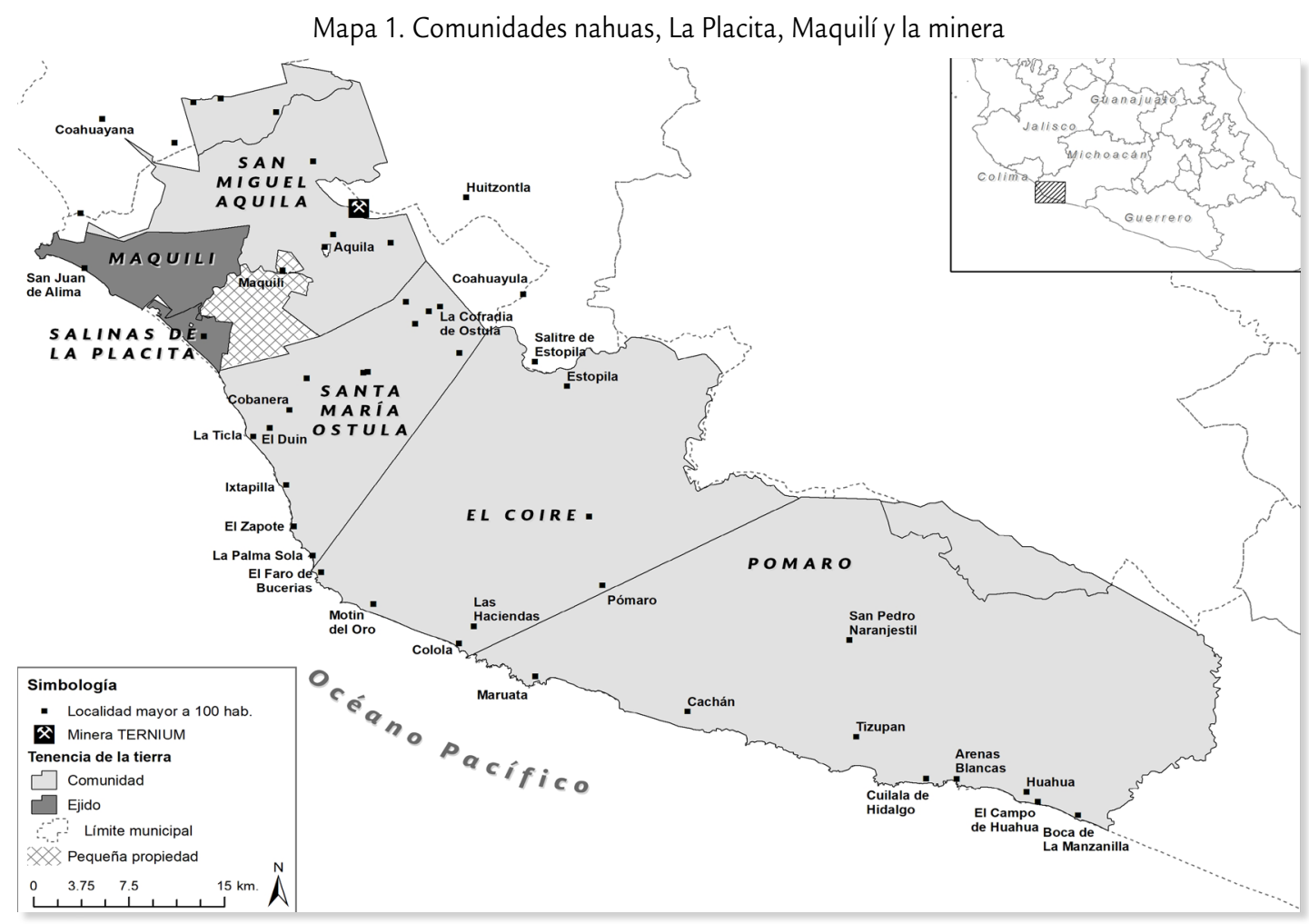

Fuente: Núcleos agrarios RAN-INEGI (SIGSEG, al 31 de diciembre de 2004). Límites municipales MG2010. Elaboración: Carmen Ventura, Dibujo: Marco A. Hernández. Colmich. SIG. 2019 
En esta ocasión, organizaron y revivieron a la policía comunitaria, ahora llamada guardia comunal, con la finalidad de resguardar su territorio. Cerca de 200 guardias comunales armados entraron al predio y junto con cientos de comuneros levantaron en 23 días 23 casas, una por cada una de las encargaturas del orden, quienes fueron:

[...] recibidos por un grupo de sicarios a balazos; afortunadamente solo un compañero resultó herido. La situación se tornó muy complicada, muy compleja en aquella ocasión. Afortunadamente, también, las comunidades hermanas indígenas nahuas de Pómaro y Coire enviaron refuerzos y enviaron bastimentos a la comunidad de Santa María Ostula y en los siguientes días se organizó una verdadera defensa comunal con el apoyo de las tres comunidades. (Octubre19, 2014)

EI TSA revisó nuevamente el caso y lo turnó en 2010 al TUA ordenando la reposición del proceso. En esta fase jurídica se encontraban cuando secuestraron en abril de ese año a Francisco de Asís Manuel, presidente del Comisariado de Bienes Comunales. El asesor legal acudió al TUA para notificar del secuestro y solicitar que cambiaran al perito designado por la Comisión Nacional para el Desarrollo de los Pueblos Indígenas (CDI) y proponer a otro, el magistrado decidió suspender el juicio por falta de garantías en la comunidad, pero no aceptó cambiar al perito. Por su parte, los pequeños propietarios interpusieron un amparo contra la suspensión del juicio, el cual ganaron, por lo que, se reactivó el proceso en octubre de 2013. La representación legal de la comunidad solicitó varias prórrogas y el magistrado finalmente aceptó al perito propuesto por la comunidad. Finalmente, el TUA a principios del 2019 emitió la sentencia, la cual fue desfavorable para Ostula, proceso que de nueva cuenta presentó una serie de irregularidades, por ello, la comunidad interpuso un recurso una vez más ante el Tribunal Superior Agrario, ahora habrá que esperar el desenlace jurídico. Sin embargo, la situación es mucho más compleja, rebasa la dimensión agraria, un funcionario agrario advierte que, aunque el tribunal dicte una Resolución "ino se va a poder ejecutar nunca!"”,

9 Entrevista con un funcionario de SRA, quien solicitó no ha- debido a la capacidad organizativa de la comunidad, la situación de violencia que se vive en la región y por los intereses que tienen distintos actores en ese territorio. Un miembro del consejo comunal de Ostula señala: "[...] vamos a resistir, no vamos a permitir que vengan a imponer, que vengan a reprimirnos con sus nuevas instituciones de seguridad, como la Guardia Nacional, no lo vamos a permitir, vamos a levantar la voz, a difundir en los medios lo que nos puede pasar, de aquí no nos vamos a salir, sabemos con certeza que estas tierras nos pertenecen" 10 .

La definición de la "mojonera 149" es importante porque de ahí se parte en dirección norte hacia el cerro denominado San Franciscote, comprendiendo una franja costera que sube a la Sierra, de cerca de 10 mil hectáreas y que colinda con uno de los beneficios de la minera trasnacional Ternium, que comentamos anteriormente. A decir de los comuneros, esta empresa tiene interés en construir en esta superficie un ferroducto, que le permitiría disminuir los costos de transporte, además de su interés por explotar los minerales (oro, plata y fierro) existentes en la comunidad.

El proceso de Ostula generó la solidaridad en un primer momento de las vecinas comunidades nahuas de Coire y Pómaro, las cuales también organizaron lo que fueron las primeras policías comunitarias en el estado ${ }^{11}$. Como una muestra de su respaldo, al igual que Ostula, se negaron a participar en las elecciones federales de 2009 no dejando instalar las casillas. A la problemática jurídica se agrega el clima de violencia y la participación de otros actores, que en la costa le denominan "la maña", refiriéndose a grupos del crimen organizado vinculados con estos rancheros mestizos que se autodenominan pequeños propietarios, con quienes sostienen el conflicto agrario, construyendo un escenario cruzado por distintos intereses. Uno de los comuneros,

cer pública su identidad, 10 de noviembre de 2011.

10 Entrevista a un comunero, me reservo su nombre para no poner en riesgo su seguridad, debido al contexto de violencia que se vive en la región, 29 de junio de 2019.

11 El primer cuerpo de seguridad comunitaria fue en 2005 organizado por la comunidad purhépecha de Nurío. 
quien posteriormente fue el comandante de las policías comunitarias en la región, señaló:

[...] la descomposición inició en 2010, cuando Mario Álvarez López (a quien el gobernador Fausto Vallejo nombró en marzo de 2012 como delegado regional de la Secretaría de Desarrollo Rural del Gobierno de Michoacán en Coahuayana) se lanzó a la diputación federal por el PRI: Logró cooptar a unos 20 líderes de Ostula y les pegó una calca de 'Yo soy del PRI', con eso se rompió el acuerdo de cero partidos. (comunero, en Guillén, 2016, p. 63)

Mario Álvarez es uno de los pequeños propietarios con los que Ostula sostiene el conflicto. Fue presidente municipal en dos ocasiones (19931995 y 2005-2007), tesorero del ayuntamiento y candidato por la diputación local de Coahuayana en 2011. De acuerdo con la versión de los comuneros, tiene fuertes vínculos con el jefe de la "maña" asentado en La Placita (Guillén, 2016).

En seguida exponemos cómo el asunto agrario se complejiza, debido a que se encuentra inmerso en un contexto de violencia protagonizada por miembros del crimen organizado. El territorio es disputado por distintos actores. Por su parte, la presencia del Estado se expresa en ocasiones en ausencia, otras en complicidad o bien en acciones de fuerza en contra de los procesos organizativos comunales, pero sin tomar medidas que trastoquen las estructuras de la economía ilegal. Como afirma Gledhill, es una especie de "Estado fantasma" que nos devela que: "detrás de la fachada del Estado respetable e institucional [...], [existe] una red de relaciones que implicaba no solamente la corrupción sino también relaciones clandestinas con el crimen organizado" (Gledhill, 2013, p. 8).

\section{Crimen organizado y violencia en Ostula}

La presencia del narcotráfico no es nueva en la historia del estado, por lo menos en esta región geográfica de Tierra Caliente, Sierra y Costa. Los cultivos ilícitos eran parte de los paisajes del sur michoacano desde la segunda mitad hasta fines del siglo XX, momento en que el negocio se expandió a la industria de las metafentaminas. Este periodo que fue el de mayor crecimiento para el llamado Cártel Milenio o de los hermanos Valencia, cuyo control se extendía hasta los estados vecinos de Jalisco, Colima y Nayarit (Astorga, 2003). Poco tiempo después, con el arribo del entonces brazo armado del Cártel del Golfo, los denominados Zetas lograron debilitar a los hermanos Valencia, no solo a través de la violencia, sino también porque varios de sus miembros cambiaron sus lealtades. La clase política estatal y regional también se adecuó a los nuevos tiempos. Con ello inició no solo una ola de terror, sino que además ampliaron su economía a otras actividades ilícitas como el secuestro, extorsión, cobro de piso y despojo de propiedades, siendo la población civil la más afectada.

Salvador Maldonado señala que a partir de la escisión del Cártel Milenio surge el grupo denominado "la Familia Michoacana que desafía más abiertamente el proyecto cultural y político del Estado" (Maldonado, 2013, p. 13) y que logra instituirse por momentos como una especie de poder paralelo en varias regiones de la entidad entre 2008 y 2010. Los Caballeros Templarios surgen en 2011, tras el anuncio de la supuesta muerte de su principal líder en un combate con las fuerzas federales, encabezados por "Servando Gómez La Tuta y José de Jesús Méndez alias El Chango, como líderes de facciones rivales. Así, mientras el primero anunció la formación del nuevo grupo [...], el segundo se aferró a seguir operando bajo el antiguo apelativo hasta su captura en junio de 2011" (Romeo LopCam, 2014).

Fueron los Caballeros Templarios quienes además de continuar con el negocio de las drogas también retomaron las otras actividades de secuestro, cobro de piso, así como extorsión a los empresarios limoneros y aguacateros $y$, el despojo de sus propiedades. Incursionaron en otros sectores de la economía, como la rentable explotación minera y maderera y su exportación a China. Fueron bastante hábiles para establecer una compleja y amplia red de relaciones con representantes de distintos ámbitos de gobierno, desde los ayuntamientos, apoyando a candidatos a presidentes municipales sin importar su 
militancia partidaria, a cambio del control de la policía municipal y de la dirección de obras, así como de una 'cuota' destinada para el funcionamiento 'de la empresa' (como denominan sus propios integrantes al negocio del narcotráfico). Lo anterior encuentra sustento en la serie de videos que circularon en las redes sociales y que llevaron a varias detenciones y al encarcelamiento de algunos integrantes de la clase política estatal, como la del propio secretario del gobierno estatal Jesús Reyna García (El sol de México, $22 / 12 / 2018)^{12}$, quien además fungió como gobernador interino (abril 2013-octubre 2013) -durante la administración del gobernador Fausto Vallejo (2012-2014)-, así como la del propio Rodrigo Vallejo ${ }^{13}$, hijo del gobernador, al igual que 11 alcaldes municipales. Esto representó una especie de "captura de pedazos de un Estado fragmentado", como lo refiere Gledhill (2014, p. 51), que evidenció una estrecha y compleja red de complicidades entre la clase política estatal y municipal con grupos del crimen organizado.

Este escenario de inestabilidad política y de violencia insostenible afectó a una gran parte de la población civil en su vida cotidiana, lo que explica el surgimiento de las autodefensas en Tierra Caliente en 2013. Los Caballeros Templarios a través de su poder territorial ejercido estaban imponiendo sus propios códigos, cobrando sus propios impuestos y logrando casi el monopolio de la coerción en prácticamente todo el territorio estatal, a través de su estrecha relación con los poderes gubernamentales y con sectores del capital nacional e internacional. Muestra de ello fue el saqueo de cerca de 300 mil toneladas de hierro de procedencia ilícita que fueron encontrados en bodegas de cuatro barcos chinos en los puertos de Manzanillo en el estado de Colima y en el de Lázaro Cárdenas en Michoacán. Constituyendo verdaderas "zonas

12 Preso de abril de 2013 a diciembre de 2018.

13 Fue condenado a 11 meses de prisión, de los cuales solo estuvo poco más de 8 meses (del 01 de agosto de 2014 al 12 de abril de 2015), tras cubrir una fianza de 7 mil pesos fue liberado (El Financiero, 11/09/2015). A fines de enero de 2019, nuevamente fue detenido acusado del delito de delincuencia organizada (Expansión Política, 26/01/2019) marrones" que de acuerdo con Guillermo O'Donnell (2004), son los lugares donde el Estado tiene una pálida presencia o es territorialmente evanescente, donde hay poderes territoriales que imponen sus códigos legales, cobran sus propios impuestos y algunas veces logran casi el monopolio de la coerción en su territorio. La explotación y traslado de esas enormes cantidades de minerales sin que las autoridades correspondientes hayan actuado al respecto por todo este tiempo, solo se explica por la complicidad de una serie de funcionarios, esto refiere a una "captura de pedazos de un Estado fragmentado" (Gledhill, 2014, p. 51).

En medio de esta cruenta disputa, la comunidad de Ostula ha tenido que pagar un alto costo humano, en estos casi diez años que recuperaron su territorio, han sido asesinados 36 comuneros $y$ hay seis desaparecidos, varios de ellos fueron presidentes del Comisariado de Bienes Comunales, responsables de la policía comunitaria y encargados del asentamiento de Xayakalan. Uno de los asesinatos que representó un duro golpe a la organización comunitaria fue el de Don Trino quien fungió como responsable del asentamiento, ocurrido el 6 diciembre de 2011. Ese día regresaba a Ostula, después de permanecer un tiempo fuera de la comunidad para reponerse de las heridas que sufrió en un atentado, venía acompañado por miembros del Movimiento por la Paz con Justicia y Dignidad, sin embargo, justo en la entrada de Xayakalan fue secuestrado y asesinado por un grupo de jóvenes, acusado de ser "Zeta" (Guillén, 2016, p. 75). Lo anterior es muestra de la complejidad de estos procesos donde las líneas de intereses y lealtades comunales se difuminan, además de que estas son cambiantes. Las estrategias de 'la maña' no son necesariamente el convencimiento sino también la amenaza y la coerción, que en Ostula no son una promesa sino una realidad que se impone violentamente de manera cotidiana.

Ese mismo día que mataron a Don Trino estaba convocada la asamblea comunal para conocer la propuesta gubernamental por parte de los funcionarios del programa federal deno- 
minado Conflictos Sociales en el Medio Rural (Cosomer) ${ }^{14}$, cuyo propósito era presentar una serie de posibilidades para resolver el conflicto agrario; reunión que por supuesto no se efectuó. Ante estas condiciones de total impunidad y de violencia, las autoridades federales y estatales han incumplido los compromisos de las medidas cautelares consistentes en proporcionar protección a los comuneros que otorgó el 25 de septiembre de 2010, la Comisión Interamericana de Derechos Humanos (CIDH) a la comunidad de Ostula.

Esta serie de hechos mermaron significativamente a la comunidad, varios de sus líderes tuvieron que salir para salvaguardar sus vidas y las de sus familias. Durante estos años, en Ostula se vivió un verdadero clima de terror e incertidumbre. Fue hasta febrero de 2013 que hubo nuevas condiciones que permitieron el retorno de varios comuneros y la reorganizaron de su policía comunitaria. La coyuntura política y social que contribuyó a su regreso fue el surgimiento de las autodefensas en el estado.

Si bien la reorganización de la policía comunitaria en Ostula resurge en este contexto, tiene sus propias particularidades. Este cuerpo de seguridad comunal formaba parte de su organización social, pocos años atrás había sido desmantelado por las autoridades municipales. Una diferencia sustancial de la guardia comunal en relación con las autodefensas que surgieron en Tierra Caliente es que la primera es nombrada por la asamblea comunal, por tanto, como bien señalan: "A quien obedecemos es al pueblo, no al gobierno federal" (Página 24, 01/05/2014). Gledhill, sostiene que "ser policía es un tipo de servicio comunal, que tocará a casi todos los comuneros en el transcurso de sus vidas, y sin goce de sueldo" (2013, p. 6). Dicha guardia está constituida por 180 comuneros designados por cada una de las ahora 24 encargaturas, no reciben ningún ingreso económico, son apoyados y

14 Es un programa federal diseñado en 2006 para la atención de los conflictos agrarios, en 2003 se denominó "Focos rojos". La propuesta gubernamental consistía en darles tres millones de pesos como contraprestación por renunciar al reclamo de las tierras recuperadas, la cual, los comuneros no aceptaron. vigilados por las instancias de su organización social; son miembros de una colectividad que comparte un conjunto de elementos culturales que le dan cierta cohesión, sus instituciones de defensa tienen un origen y son resultado de un largo proceso histórico, aunque no están libres de tensiones y contradicciones.

\section{REORGANIZACIÓN DE LA COMUNIDAD. GUARDIA COMUNAL, TERRITORIALIDADES EN DISPUTA}

Ante el clima de violencia que prevalecía en Michoacán a principios de 2013, el presidente de la República nombró a un comisionado especial para atender la situación de emergencia. Este personaje cumplió en los hechos las funciones de gobernador, en un inicio se apoyó en las Autodefensas surgidas en cerca de 28 municipios (Proceso, 29/12/2013), poco tiempo después promovió su institucionalización, a través de distintos cuerpos de seguridad (Fuerza Rural y Fuerza Ciudadana), para contrarrestar la presencia de los líderes de estas iniciativas armadas. Antes del surgimiento de las Autodefensas, la comunidad de Ostula ya había nombrado a un comunero como comandante de su guardia comunal, quien tiempo después fue nombrado por las propias Autodefensas como coordinador general de los municipios de Aquila, Coahuayana y Chinicuila de la costa michoacana, quienes se resistieron a este proceso de institucionalización.

La organización comunitaria de defensa logró que el jefe de la plaza de Los caballeros templarios, Mario Álvarez -integrante de la cúpula de la estructura priísta en la región y uno de los pequeños propietarios con quienes se disputan el territorio en conflicto-, se fuera de La Placita, así como otros tantos miembros del crimen organizado que tenían asolada a la región. El asentamiento de Xayakalan que había reducido su presencia a unas 10 familias de las 40 que llegaron a vivir ahí, pronto recuperó su dinamismo, al retornar nuevamente varias de las familias ${ }^{15}$. En febrero de 2013 hubo un intento de desalojo por parte del Ministerio

15 En junio de 2019 viven en Xayakalan 75 familias. 
público que logró detenerse gracias al fortalecimiento de la organización comunal, de su policía y del apoyo de las autodefensas del municipio de Aquila. La guardia comunal es la encargada de la seguridad, realiza rondines por el territorio y cuida el asentamiento de Xayakalan, responsabilidad que recae en cada una de las 24 encargaturas, que se rolan por día.

Después de varios atentados en contra del comandante de la guardia comunal de Ostula, de los que salió ileso, aunque con un saldo de varios comuneros muertos y heridos, en julio de 2015 fue detenido y acusado de cuatro delitos: 1) violación a la Ley Federal de Armas de Fuego y Explosivos; 2) robo calificado; 3) robo y quema de urnas y; 4) homicidio. La comunidad respondió con un bloqueo en la carretera costera para demandar la libertad del comandante, sin embargo, fueron agredidos por miembros del ejército, resultando un niño muerto y cuatro comuneros lesionados. Finalmente, en diciembre de ese año, el comandante fue liberado por falta de pruebas. Sin embargo, poco después de obtener su libertad, su lealtad comunal empezó a ser cuestionada y nunca fue integrado nuevamente en su carácter de comandante. En las elecciones federales de 2018, sin el respaldo de la comunidad, el excomandante se postuló como candidato a diputado local por el Partido de Acción Nacional (PAN), lo que significó una ruptura con la comunidad; en una asamblea realizada en julio de ese año, se decidió su expulsión, no solo por este acercamiento político, sino porque se la había visto en actos públicos en compañía de miembros de los grupos que han violentado a la comunidad (SubVersiones, 09/07/2018).

La comunidad de Santa María de Ostula pertenece desde hace varios años al Congreso Nacional Indígena (CNI), organización ligada al Ejército Zapatista de Liberación Nacional (EZLN). En el proceso electoral federal de 2018 el CNI apoyó la postulación de una mujer indígena a la presidencia de la República. Ostula fue una de las comunidades que visitó esta candidata y en la que obtuvo un respaldo importante, sin embargo, las firmas en apoyo a su candidatura a nivel nacional en su carácter de independiente no fueron suficientes para lograr su registro. A la par de las elecciones federales, hubo elecciones estatales y municipales. En el municipio de Aquila al que pertenece la comunidad de Ostula obtuvo el triunfo el candidato del Partido Verde Ecologista de México (PVEM), quien a decir de los comuneros está ligado con "la maña", por lo que, el escenario para la comunidad vuelve a ser complicado y en estado de alerta, por la recomposición de algunas células del crimen organizado de los otrora Caballeros Templarios, ahora denominados "Viagra" y por la incursión de miembros del denominado Cártel Jalisco de Nueva Generación (CJNG).

A pesar de estos escenarios adversos, los nahuas de Ostula han sido capaces de: parar el proceso de despojo, fortalecer sus estructuras comunales, reorganizar a su guardia comunitaria y otorgar seguridad en la costa. En su momento, representaron un gran obstáculo para el proceso de institucionalización de las otrora autodefensas que promovió el entonces comisionado Alfredo Castillo ${ }^{16}$. Su presencia y rebeldía cuestionan las políticas de seguridad y quiebran el intento de control estatal y del narcotráfico sobre el territorio de la costa, obstaculizan la libre circulación de bienes ilegales, impiden continuar con los trabajos de saqueo de los recursos como el de maderas preciosas con destino a China y Taiwán (Guillén y Torres, 2014), ponen en riesgo la explotación de oro y plata que existe de manera 'clandestina' y merman las ganancias de la extracción de minerales de una de las empresas mineras más grandes del mundo, así mismo complican el panorama para el inicio de los trabajos de las nuevas concesiones mineras ya contempladas en la región. Como señaló el entonces presidente municipal de Aquila:

[...] la zona más afectada por la minería ilegal fue la sierra de la Barranca de López [...] la empresa Ternium está presionando al gobierno estatal para que se cambie el Ordenamiento Ecológico

16 La figura de Comisionado se disolvió a principios de 2015 ante el inicio del proceso electoral estatal para renovar presidencias municipales, el congreso local y la gubernatura, en junio de ese año. 
Regional Sierra-Costa, pues actualmente no permite la minería, lo que le impide a la firma expandirse. (Página 24, 01/05/2014)

Así también, los comuneros de Ostula frenan la puesta en práctica de los proyectos turísticos por parte del gobierno estatal con capital trasnacional. Las comunidades de Aquila y Ostula son los únicos núcleos agrarios en ese municipio que no han aceptado los programas federales de certificación de la tierra ${ }^{17}$, PROCEDE y FANAR ${ }^{18}$, condición necesaria para la legalización del mercado de tierras. En suma, representan una amenaza a la reproducción del sistema económico en el que se encuentran imbricadas las estructuras políticas y el narcotráfico de todo tipo.

A pesar de que en marzo de 2016 el municipio de Aquila aceptó el Mando Único propuesto por el actual gobernador perredista Silvano Aureoles (2015-2021), la guardia comunal de Ostula mantiene en sus manos su seguridad y los puestos de control, aunque en constante tensión con los distintos cuerpos de seguridad estatal y federal. En marzo de 2017 se inauguró una base naval en la localidad de La Placita y se anunció la creación de dos más, una en Coahuayana y la otra en Caleta de Campos, flanqueando a la comunidad de Ostula. En este acto el gobernador señaló: "ya no es tiempo de que ciudadanos actúen fuera del marco de la ley, y no hay cabida para grupos delictivos en esta región de la entidad" (Posta, 06/03/2017).

A partir de estos procesos, podemos señalar que si bien la tierra es considerada como soporte material de los conflictos, también es a su vez el centro de las disputas, ya sea por individuos, colectividades, empresas nacionales o trasnacionales, el propio Estado y los grupos del crimen organizado (que ahora constituyen un actor poderoso en nuestra realidad nacional),

17 De los ocho núcleos agrarios que se ubican en el municipio de Aquila, seis aceptaron los programas de certificación, cuatro ejidos y dos comunidades agrarias. En tres ejidos han adquirido dominio pleno en poco más de 707 hectáreas (Gobierno de México s/f).

18 Programa de Certificación de Derechos Ejidales y Titulación de Solares Urbanos y Fondo de Apoyo para núcleos agrarios sin regularizar. que luchan por su apropiación material y por definir el uso, disfrute, control y aprovechamiento de los recursos naturales contenidos en ese espacio geográfico. La construcción del territorio conlleva necesariamente relaciones de poder, que se entretejen más allá del espacio disputado, como bien se expresa en el proceso de defensa del territorio de Ostula, cuyos intereses traspasan las fronteras nacionales. El territorio implica "apropiación, delimitación, frontera y defensa" (Echeverría, 2001, p. 221); son estas prácticas espaciales ejercicios de territorialidad. En junio de 2015 la asamblea comunal decidió realizar un reparto de las tierras recuperadas y asignarlas para su cultivo a comuneros, como una manera de resguardo de su territorio y como un ejercicio de territorialidad. El entonces presidente del Comisariado de Bienes Comunales advirtió a los comuneros que la tierra es de la comunidad:

Hoy beneficiamos a 54 comuneros o familias con un terreno de 100 metros de boca por 200 de altura, o sea, dos hectáreas. Fue en base a las disposiciones de la ley agraria en su capítulo 99, al convenio 169 de la OIT y a los usos y costumbres que se decidió el tipo de reparto que se haría. Las tierras son inalienables, es decir, que no pueden venderse, regalarse, abandonarse o cosas parecidas; son inembargables y también son imprescriptibles, o sea que nadie puede decir que son suyas, aunque hayan pasado 30 o 40 años. Las tierras siempre serán de la comunidad. (SubVersiones, 26/06/2015)

\section{Consideraciones}

Los fenómenos descritos anteriormente nos remiten a lo señalado por Harvey, consistentes en la llamada acumulación por desposesión que revela un rango amplio de procesos, que con sus particularidades son observables en la región, como: 1) el despojo territorial al inicio de la Colonia, al considerar las tierras como realengas, luego a través de la reducción de las mismas, resultado de las leyes liberales y de la reforma agraria, durante los siglos XIX y XX; 2) la explotación de la fuerza de trabajo y su separación de los medios de producción; 3) el extractivismo de los recursos naturales (madera y minerales, principalmente por parte de extranjeros) como materia prima de expor- 
tación; 4) la legalización de conversión de la propiedad social a privada, la circulación de la tierra como mercancía en el mercado (vía enajenación y arrendamiento), a consecuencia de la contrareforma agraria neoliberal de 1992 y los programas de certificación, junto con las reformas estructurales, como la ley minera, que considera a la minería como "actividad preferente"; 5) las distintas políticas a lo largo de todo este período histórico que atentan contra las economías locales, sus modos de vida, sus territorios y sus formas de organización social y política; así como por, 6) los distintos dispositivos de violencia institucional en connivencia con las economías ilegales; entre otros.

Como bien señalan Galafasi y Composto:

La acumulación basada en la depredación y la violencia extraeconómica es una dinámica continúa e inherente a la lógica del sistema capitalista que, por lo tanto, no puede reducirse a un acontecimiento histórico superado, a un mecanismo externo, o aun comportamiento excepcional y anómalo respecto a la primacía de las leyes económicas como rectoras del desarrollo del capitalismo maduro[...] los procesos de desposesión son constitutivos e intrínsecos a la lógica de la acumulación del capital. (2013, p. 78)

[... ] los inicios del nuevo siglo XXI, serán los saberes ancestrales de los pueblos originarios y comunidades campesinas, así como los bienes dela naturaleza y la biodiversidad en general, aquellos que cobren particular preeminencia como objeto de la violencia y del despojo capitalista.(2013, p. 81)

En la costa michoacana la disputa es por el territorio y el mar, las comunidades nahuas poseen y son propietarias de aproximadamente 130 kilómetros de los 262 kilómetros con los que cuenta el litoral michoacano (Marín, 2004), esto es, casi la mitad está en sus manos. Estas comunidades costeras junto con Aquila suman una superficie de poco más de 172 mil hectáreas, en las que se encuentran los codiciados recursos minerales, maderables y las playas; superficie que contrasta con las más de 500 mil hectáreas que poseían y de las que eran propietarias antes de las leyes liberales. Como bien señalaba Huber Cochet, desde hace cerca de 30 años, "la franja costera, último bastión indíge- na, se encuentra amenazada por la implantación de grandes complejos mineros (Aquila) o turísticos (Maruata) que despojarían a las comunidades indígenas de las escasas tierras que aún conservan" (1991, p. 287). La amenaza de invasión no solo sigue latente, sino que se está acrecentando por los megaproyectos actuales y la reciente aprobación de las llamadas Zonas Económicas Especiales (2017), que comprenden una serie de grandes inversiones trasnacionales para la explotación principalmente de minerales existentes en los territorios propiedad de los nahuas. El nuevo detonante del viejo proceso parece ser la reventa del complejo portuario industrial de Lázaro Cárdenas-Las Truchas. Esta transacción, planeada en 2006, que abarca los derechos de exploración y explotación minera en la sierra-costa por 20 años; se asocia al proyecto de construcción de la autopista costera, con la que se acabará de abrir toda la región al exterior, y al proyecto turístico que favorece a las grandes empresas transnacionales; al tiempo que excluye a la población nativa de los beneficios que falsamente promete la llegada de capitales. En contraparte, todo el deterioro ambiental y social que dichos megaproyectos generan tendrá que ser absorbido por la población local. De acuerdo con datos oficiales de 2017 únicamente la empresa Ternium-Las Encinasobtuvo1.000 toneladas al día de fierro en el municipio de Aquila (Secretaría de Economía, 2018). Por su parte, la:

Dirección General de Minas de la Secretaría de Economía tiene registradas en el municipio de Aquila 102 concesiones mineras, 12 de ellas operan en 7 mil 913 hectáreas de Ostula (41.6\% de las 19 mil que constituyen su territorio) y siete están a nombre de la empresa Encinas. Ésta opera desde hace décadas en la cabecera municipal y, al igual que Peña Colorada, es propiedad de la trasnacional Ternium. (Guillén y Torres, 2014, p. 17-19)

Además, su conformación geográfica de difícil acceso permite la instalación de laboratorios y el cultivo de enervantes. Como bien apunta un asesor de Ostula, ocupan una posición económica y geoestratégica relevante, "son parte de un corredor que se forma entre Manzanillo, Láza- 
ro Cárdenas y Nuevo Laredo, un corredor estratégico en el mundo. Es la entrada por el Océano Pacifico al principal mercado mundial, que es el centro y el este de Estados Unidos"19, pero también un punto de comercialización, de importación y exportación de diversos productos de China; ambos países protagonizan la hegemonía económica mundial. En efecto, es un corredor de suma importancia para los grupos del crimen organizado, por ello, las acciones comunitarias en defensa del territorio atentan contra estos intereses que rebasan por mucho las fronteras nacionales. Falta conocer la sentencia que emitan las instancias agrarias sobre el conflicto agrario, este momento puede desatar una nueva situación de emergencia en la región, aunque la dimensión agraria es solo una de las caras de esta disputa por los recursos.

La respuesta estatal ha sido la represión a las iniciativas comunitarias, el intento de institucionalización de sus policías y la militarización de la región, como parte de una estrategia que se reproduce en otras partes del país, cada vez es más frecuente observar: instalaciones militares cerca de las explotaciones mineras y en territorios con presencia de narcotráfico ${ }^{20}$, como una especie de lo que hemos llamado un "trinomio espacial de la violencia". La creación de una base naval muy cercana al predio de Xayakalan y el anuncio de la construcción de dos más a escasos kilómetros, sugiere una política de contrainsurgencia que busca criminalizar los movimientos de resistencia en contra del despojo, como así lo refieren los asesores y comuneros (Guillén, 2016). De acuerdo con Vite Pérez:

[...] la ilegalidad también ha sido usada por el Estado mexicano para intervenir en los conflictos sociales y reproducir, bajo la ideología de la inseguridad pública, mecanismos de control social punitivos contra los que han sido clasificados como criminales y que viven la globalización desde abajo. (2016, p. 117)

19 Entrevista a asesor, me reservo su nombre para no poner en riesgo su seguridad, debido al contexto de violencia que se vive en la región, 30 de agosto de 2014.

20 Como lo pretenden hacer en el Valle de Tlacolula, Oaxaca, en donde se han contabilizado hasta 39 concesiones mineras (El Universal, 26/03/2017)
Como bien advierte John Geldhill, uno de los ejes rectores del actual modelo de acumulación por desposesión en América Latina es el nexo entre seguridad y desarrollo. La lógica de "seguridización" en clave contrainsurgente, cuyo blanco no son precisamente los grupos del crimen organizado o el narcotráfico sino los movimientos sociales que ponen en riesgo el desarrollo de megaproyectos sobre recursos naturales estratégicos, la seguridización sirve como herramienta para construir territorios de intervención y justificar un alto grado de autoritarismo por parte de los administradores del orden público (Gledhill, 2014).

La comunidad de Ostula no constituye una colectividad homogénea y libre de conflictos, las lealtades de sus miembros también pueden ser cambiantes. La hegemonía comunal se encuentra en frágil equilibrio, y es resultado de la confrontación de distintos proyectos de comunidad, cruzados por diversos intereses que forman parte de relaciones y redes de poder más allá del ámbito comunal y en un contexto de extrema violencia que permea la vida cotidiana de sus miembros. Los procesos que hemos descrito ponen a prueba su comunalidad, sus instancias de decisión, sus formas de gobierno, su territorio y con ello su hábitat. Estos proyectos económicos no sólo amenazan la continuidad de formas particulares de apropiación del espacio y de aprovechamiento de recursos, sino también la reproducción de su vida ritual y de sus relaciones de reciprocidad, en pocas palabras, de su permanencia como pueblo. No obstante, la resistencia también ha estado presente en estos procesos históricos. Como bien refirió uno de los comuneros durante la celebración del décimo aniversario de la recuperación de las tierras: "seguiremos resistiendo porque ya vivimos un proceso de maldad, donde hubo muertos, levantones, desaparecidos, familias viudas, hijos huérfanos y no queremos que se repita la misma historia". ${ }^{21}$

A pesar de la complejidad de este escenario, hay nahuas que afirman que no están dispues-

21 Entrevista a un comunero, me reservo su nombre para no poner en riesgo su seguridad, debido al contexto de violencia que se vive en la región, 29 de junio de 2019. 
tos a dejar su territorio. Una pareja de esposos, de edad avanzada, sostuvieron con voz firme:

[...] ahí estamos, entre el valor y el miedo, como luego se dice, porque no es puro valor que tenemos, tampoco es puro miedo que tenemos, ahí estamos entre que sí $y$

\section{REFERENCIAS}

Astorga L. (2003). Drogas sin fronteras. México: Grijalbo.

Cochet, H.; De Surgi, J-D. y Leonard, E. (1988). Paisajes agrarios de Michoacán. Zamora, Michoacán: El Colegio de Michoacán.

Cochet, H. (1991). Alambradas en la sierra. México: CEMCA / ORSTOM / COLMICH.

Echeverría Ramírez, M. (2001). Descentrar la mirada: avizorando la ciudad como territorialidad (pp. 217-249). En Espacio y territorios. Razón, pasión e imaginarios. Colombia: Universidad Nacional de, Red de Estudios de Espacio $y$ territorio, RET.

Galafassi, G. y Composto, C. (2013). Acumulación por despojo y nuevos cercamientos: el caso de la minería a gran escala en la Patagonia Argentina. Cuadernos del CENDES, 30, (83), 75-103. Recuperado de https://www.redalyc. org/pdf/403/40329473005.pdf

Gledhill, J. (2004). Cultura y Desafío en Ostula. Zamora, Michoacán: El Colegio de Michoacán.

Gledhill, J. (2013). Límites de la autonomía y autodefensa indígena: experiencias mexicanas. Oximora, Revista Internacional de Ética y Política, (2), 1-21.

Gledhill, J. (2014). Seguridizar, reprimir, pacificar: una crítica de las nuevas guerras en América Latina (pp. 31-62). En L.R. Valladares de la Cruz (Coord.) Nuevas violencias en América Latina. Los derechos indígenas ante las políticas neoextractivistas y las políticas de seguridad. México: UAM Iztapalapa, Juan Pablos Editor, México.

Guillén, A. (2016). Guardianes del territorio. Seguridad y justicia comunitaria en Cherán, Nurío y Ostula. Barricadas Colección. México: Grietas Editores.

Harvey D. (2004). El nuevo imperialismo. Madrid: Akal.

HarveyD.(2005). El 'nuevoimperialismo':acumulaciónpor que no, pero decimos que no nos vamos a ir de aquí [Xayakalan], de lo contrario se va a plantar más gente, se va a hacer el rancho grande, aquí no vamos pa ' tras $^{22}$.

22 Entrevista a Don P y su esposa, comunero de Ostula, 22 de septiembre de 2011.

desposesión. Clacso. Recuperado de http://biblioteca.clacso.edu.ar/clacso/se/20130702120830/ harvey.pdf (consulta 10/04/2017).

Maldonado, S. (2013). Geografía de la violencia en México: Enfrentar el crimen en medio del narcotráfico y la delincuencia organizada. Boletim Gaúcho de Geografia, (40), 13-33. Recuperado de https://seer.ufrgs.br/bgg/article/ view/39793/25534 (consulta 10/04/2017).

Marín, G. (2004). Etnicidad, territorio y cultura en la costa nahua de Michoacán (pp. 243-273). En G. Marín (Comp.) El fin de toda la tierra, historia, ecología y cultura en la costa de Michoacán. Zamora, Michoacán: El Colegio de México, Centro de Investigación Científica y de Educación Superior de Ensenada, El Colegio de Michoacán.

Novella, R. (1996). La Costa de Michoacán, Mejico, en el siglo XVI. Anales del Museo de América, (4), 25-37.

O' Donnell, G. (2004). Notas sobre la democracia en América Latina (pp. 11-82). En La democracia en América Latina. El debate conceptual sobre la democracia. Perú: PNUD.

Reyes García, C. (1993). Los centinelas del mar del sur. Relaciones, XIV(55), 139-161.

Sánchez Díaz, G. (2010). La Costa de Michoacán, espacio y tiempo (pp. 23-42). En G. Sánchez Díaz y A. Ríos Szalay La costa michoacana, perfil de un paraíso. Barcelona: UNMSH - Gobierno de Michoacán - Lunwerg.

Sánchez Díaz, G. (2013). La ferrería de Coalcomán: Recuperación de una historia olvidada. Morelia: Universidad Michoacana de San Nicolás de Hidalgo.

Vite Pérez, M. (2016). Los territorios ilegales mexicanos y la violencia regional en Michoacán. Política y Cultura, (46), 101-117. 


\section{OTRAS FUENTES}

Agencia prensa india API (s/f). Kayakalan el inicio. Recuperado de http://www.youtube.com/ watch? $v=P 3 y y p 2 i W a V s \&$ feature $=$ related $($ consulta 15 y 16 de enero 2012)

Aquila. Recuperado de https://es.wikipedia. org/wiki/Municipio_de_Aquila_(Michoac\%C3\%A1n) (consulta 31 de marzo 2020).

El Financiero (11/09/2015). Rodrigo Vallejo recibe condena por encubrir a 'La Tuta' pero 'libra' cárcel. Recuperado de http://www.elfinanciero.com.mx/ nacional/rodrigo-vallejo-recibe-condena-por-encubrir-a-la-tuta-pero-libra-carcel.html.

El Sol de México (22/12/2018). Sale libre Jesús Reyna García, exgobernador de Michoacán. Recuperado de https://www.elsoldemexico.com.mx/mexico/justicia/sale-libre-jesus-reyna-garcia-exgobernador-de-michoacan-2834171.html

El Universal (26/03/2017). Se oponen comunidades de Oaxaca a nuevas instalaciones militares. Recuperado de http://www.eluniversal.com.mx/ articulo/estados/2017/03/26/se-oponen-comunidades-de-oaxaca-nuevas-instalaciones-militares

Expansión Política (26/01/2019). Detienen (otra vez) al hijo del exgobernador Fausto Vallejo. Recuperado de https://adnpolitico.com/mexico/2019/01/26/detienen-otra-vez-al-hijo-delexgobernador-fausto-vallejo (consulta 5 de enero 2019).

Gobierno de México (s/f). Registro Agrario Nacional. Recuperado de http://www.ran.gob.mx/ ran/index.php/sistemas-de-consulta/phina

Octubre19 (25/06/2014). Comunitarios de Ostula en Casa Lamm Asesor. Recuperado de http:// www.youtube.com/watch?v=b7JXFvXjFM8 (consulta 19 de septiembre 2014).

Página 24 (01/05/2014). No se registrarán en Santa María Ostula. Recuperado de http://pagina24.

\section{ENTREVISTAS}

Entrevista a asesor, me reservo su nombre para no poner en riesgo su seguridad, debido al contexto de violencia que se vive en la región, com.mx/nacional/2014/05/01/no-se-registraran-en-santa-maria-ostula/

Panorama Minero del Estado de Michoacán (2017). Recuperado de http://www.sgm.gob. $\mathrm{mx} / \mathrm{pdfs} / \mathrm{MICHOACAN}$.pdf (consulta 30 de enero 2019).

Posta (06/03/2017). Inauguran Base Naval en Michoacán. Recuperado de http://www.posta. com.mx/michoacan/inauguran-base-naval-en-michoacan (consulta 09 de abril 2017).

Proceso (15/02/2014). La violencia, también por las minas y la madera. Recuperado de https://www. proceso.com.mx/365015/la-violencia-tambien-por-las-minas-y-la-madera

Proceso (29/12/2013). Autodefensas controlan 28 municipios de Michoacán. Recuperado de http:// www.proceso.com.mx/361314/autodefensas-controlan-28-municipios-demichoacan (consulta 18 de julio 2016).

Resolución Presidencial (27/04/1964). Publicada en el Diario Oficial de la Federación. Recuperado de http://dof.gob.mx/nota_to_ imagen_fs.php?cod_diario=206680\&pagina $=13 \&$ seccion $=0$

Secretaría de Economía (2018). Panorama Minero del Estado de Michoacán. Recuperado de http://www.sgm.gob.mx/pdfs/MICHOACAN.pdf

SubVersiones (05/02/2014). Brevísima historia del crimen organizado en Michoacán. Recuperado de http://subversiones.org/archivos/19328 (consulta 02 de abril 2017).

SubVersiones (26/06/2015). Reparto de tierras y reconstrucción de comunidad de Ostula. Recuperado de https://subversiones.org/archivos/116966

SubVersiones (09/07/2018). Ostula en alerta, ante la instauración del narcogobierno. Recuperado de https://subversiones.org/archivos/132787.
30 de agosto de 2014.

Entrevista a Don P y su esposa, comunero de Ostula, Xayakalan, 22 de septiembre de 2011. 
Entrevista a un funcionario de SRA, quien solicitó no publicar su nombre, Morelia 10 de noviembre de 2011.

Entrevista colectiva, miembros que resguardan las tierras comunales, 11 de septiem- bre de 2009.

Entrevista a un comunero, me reservo su nombre para no poner en riesgo su seguridad, debido al contexto de violencia que se vive en la región, 29 de junio de 2019.

María del Carmen Ventura Patiño es Doctora en Ciencias Sociales con especialidad en Antropología Social. Profesora-Investigadora. Miembro del Sistema Nacional de Investigadores, Nivel I. Ganó el Premio a la mejor tesis de Doctorado, Vania de Salles, Asociación Mexicana de Estudios Rurales 2009. Ha publicado cerca de 30 artículos y capítulos, así como 5 libros de autoría única y en coautoría sobre temas relacionados con Territorios indígenas y conflictos agrarios, Justicia indígena, Gobiernos locales y reivindicaciones autonómicas y Movimiento indígena y reformas legales. El libro Democracia, cultura política y ciudadanía en el México de hoy (L. Rodríguez, S. Hernández y C. Ventura, Coords.), edición CIMSUR-, fue seleccionado -de entre más de 100 libros y 40 artículos académicos- por Shannan Mattiace, editora de la sección mexicana del "Handbook of Latin American Studies, edición 2017", como una de las mejores producciones académicas para comprender la política en México. La obra será reseñada en el Handbook of Latin American Studies, vol. 73, coordinado por la biblioteca del Congreso Estadounidense (Library of Congress). Haciendo mención especial al capítulo: "Democracia y ciudadanía en la meseta purhépecha de Michoacán" de su autoría. El último libro coeditado es Derechos indígenas en disputa, legislaciones estatales y tensiones locales. Centro de Estudios Rurales. El Colegio de Michoacán. Martínez de Navarrete 505, Col. Las Fuentes, C.P. 59699, Zamora, Michoacán, México, ventura@colmich.edu.mx 